\title{
Effects of $\mathrm{CB}_{1}$ and $\mathrm{CRF}_{1}$ receptor antagonists on binge-like eating in rats with limited access to a sweet fat diet: Lack of withdrawal-like responses
}

\author{
Sarah L. Parylak $\# a, b$, Pietro Cottone ${ }^{\# a, c,{ }^{* *}, \text { Valentina Sabino }}{ }^{a, c}$, Kenner C. Rice $^{d}$, and Eric P. \\ Zorrillaa,b, ${ }^{a}$ \\ aCommittee on the Neurobiology of Addictive Disorders, SP30-2400, The Scripps Research \\ Institute, 10550 N Torrey Pines Rd, La Jolla, CA 92037, USA \\ bNeurosciences Graduate Program, University of California, San Diego, 9500 Gilman Dr 0634, La \\ Jolla, CA 92093, USA \\ 'Laboratory of Addictive Disorders, Departments of Pharmacology and Psychiatry, Boston \\ University School of Medicine, 72 E Concord St, R-618, Boston, MA 02118, USA
}

${ }^{d}$ Chemical Biology Research Branch, National Institute on Drug Abuse and National Institute on Alcohol Abuse and Alcoholism, 5625 Fishers Lane, Bethesda, MD 20892, USA

\# These authors contributed equally to this work.

\section{Abstract}

Positive reinforcement (e.g., appetitive, rewarding properties) has often been hypothesized to maintain excessive intake of palatable foods. Recently, rats receiving intermittent access to high sucrose diets showed binge-like intake with withdrawal-like signs upon cessation of access, suggesting negative reinforcement mechanisms contribute as well. Whether intermittent access to high fat diets also produces withdrawal-like syndromes is controversial. The present study therefore tested the hypothesis that binge-like eating and withdrawal-like anxiety would arise in a novel model of binge eating based on daily 10 -min access to a sweet fat diet (35\% fat kcal, $31 \%$ sucrose kcal). Within 2-3 weeks, female Wistar rats developed binge-like intake comparable to levels seen previously for high sucrose diets ( $40 \%$ of daily caloric intake within $10 \mathrm{~min}$ ) plus excess weight gain and adiposity, but absent increased anxiety-like behavior during elevated plusmaze or defensive withdrawal tests after diet withdrawal. Binge-like intake was unaffected by pretreatment with the corticotropin-releasing factor type $1\left(\mathrm{CRF}_{1}\right)$ receptor antagonist $\mathrm{R} 121919$, and corticosterone responses to restraint stress did not differ between sweet-fat binge rats and chow-fed controls. In contrast, pretreatment with the cannabinoid type $1\left(\mathrm{CB}_{1}\right)$ receptor antagonist SR147778 dose-dependently reduced binge-like intake, albeit less effectively than in ad lib chow or sweet fat controls. A priming dose of the sweet fat diet did not precipitate increased anxiety-like behavior, but rather increased plus-maze locomotor activity. The results suggest that $\mathrm{CB}_{1^{-}}$ dependent positive reinforcement rather than $\mathrm{CRF}_{1}$-dependent negative reinforcement mechanisms predominantly maintain excessive intake in this limited access model of sweet-fat diet binges.

(C) 2012 Elsevier Inc. All rights reserved.

*Correspondence to: Committee on the Neurobiology of Addictive Disorders, SP30-2400, The Scripps Research Institute, 10550 N. Torrey Pines Road, La Jolla, CA 92037, USA. Tel.: +1 858784 7470; fax: +1 858784 7405. ezorrilla@ scripps.edu. ${ }^{\star *}$ Correspondence to: Laboratory of Addictive Disorders, Boston University School of Medicine, 72 E Concord Street, R-612, Boston, MA 02118, USA. Tel.: +1 617638 5662; fax: +1617638 5254. cottone@bu.edu.

sparylak@ucsd.edu (S.L. Parylak), vsabino@bu.edu (V.Sabino), kennerr@mail.nih.gov (K.C. Rice).

Disclosure statement EPZ is an inventor on a patent filed for CRF 1 antagonists (USPTO Application \#: \#2010/0249138). 


\section{Keywords}

Binge eating; Palatable food intake; Sucrose or sugar or fat or food addiction; Obesity; Withdrawal anxiety; Corticotropin-releasing factor or corticotropin-releasing hormone or CRF or $\mathrm{CRH}$; Endocannabinoid or cannabinoid type 1 receptor; Surinabant or rimonabant

\section{Introduction}

Binge eating in humans is defined as repeated bouts of rapid, uncontrollable and excessive food intake. Individuals differ in which specific foods trigger binge eating; common foods include high carbohydrate items, such as breads and pastas, or high fat items, such as chips and fried meats [1]. Typical rodent models of binge eating thus provide palatable foods high in sugar or fat during limited access periods with intervening phases of food deprivation or access to a less preferred food [2-6]. Such schedules lead to hyperphagia when palatable food is available, mimicking the intermittent but intense character of human binges. For example, rats provided with only 10-min daily access to a chocolate-flavored high sucrose/ low-fat diet ultimately consumed $>40 \%$ of their total daily caloric intake within those 10 $\min$ [7]. This binge-like behavior was accompanied by increased weight gain, metabolic feed efficiency, and adiposity. As part of the current study, we sought to determine whether binge-like food intake and increased obesity risk similarly developed in a novel putative model of binge eating based on daily 10-min access to a sweet, high fat diet.

It remains unclear whether motivational mechanisms that drive binge eating are shared among palatable foods, or whether certain factors differentially contribute to binging on sugar vs. fat. Anecdotal reports and the popular lay literature promote a concept of "sugar addiction" or "sugar craving" [8-10] that has begun to receive empirical support in animal models. For example, intermittent access to palatable, high sugar diets can produce withdrawal-like behavioral effects upon cessation of access. Hoebel, Avena and colleagues found that rats provided with daily 12 -h access to sugar solutions showed increased anxietylike behavior in the elevated plus-maze (10\% sucrose) [2] and opiate-like somatic withdrawal signs ( $25 \%$ glucose) after 1-2 days of food deprivation, effects that could be precipitated at earlier time points by the opioid antagonist naloxone [11]. We similarly found that rats 'cycled' between continuous access to a chocolate-flavored, nutritionally complete high-sucrose diet (50\% kcal from sucrose, 2 days) vs. chow (5 days) each week developed increased anxiety-like behavior when the palatable food was withdrawn, binge eating upon renewed access to the food, and reduced intake of and reinforcing efficacy of otherwise acceptable chow. Activation of brain stress systems via corticotropin-releasing factor $(\mathrm{CRF})$ partly mediated these effects of 'diet cycling'; pretreatment with the $\mathrm{CRF}_{1}$ antagonist, R121919 normalized anxiety-like behavior, reduced overeating upon renewed access, and partly restored chow intake at doses that did not alter behavior of controls $[12,13]$. Rats withdrawn ( $24 \mathrm{~h})$ from daily 10 -min access to the same high-sucrose diet also showed increased anxiety-like behavior [7]; moreover, greater anxiety-like behavior correlated directly with larger binges, further supporting the hypothesis that relief from anxiety-like effects of withdrawal may promote binge-like intake of high sucrose diets in negative reinforcement fashion.

In contrast to the anxiogenic-like effects reported for withdrawal from high sugar diets, the ability of abstinence from high-fat or sweet-fat diets to induce a negative state in rodents is more controversial. One group reported increased open field locomotor activity following a switch from ad libitum high fat diet access to standard chow in mice, along with an increase in CRF mRNA in the central amygdala [14]; however, anxiety-like changes in plus-maze behavior were not observed. Furthermore, whereas withdrawal ( $24 \mathrm{~h})$ from ad libitum access 
to a sweet fat diet did increase plus-maze anxiety-like behavior in rats, anxiogenic-like behavior did not result following intermittent access [15]. Moreover, neither spontaneous nor naloxone-precipitated opiate-like somatic withdrawal signs were seen in rats withdrawn from the sweet fat diet [15].

In the present study, we sought to test the hypothesis that limited access to a sweet fat diet produces motivationally-relevant withdrawal-like signs, akin to our previously studied highsucrose diet [7,12], evident as either increased anxiety-like behavior or greater sensitivity to the effects of a $\mathrm{CRF}_{1}$ antagonist on food intake. Because exposure to a craved food can precipitate binge behavior in humans with bulimia nervosa [16] and animal models [17], we also tested the hypothesis that a priming dose of the sweet fat diet might precipitate anxietylike behavior if further binge food was not available. Finally, because high fat diets engage neurotransmitter systems other than endogenous opioids, such as the endocannabinoid system [18-20], we tested the hypothesis that administration of a cannabinoid type $1\left(\mathrm{CB}_{1}\right)$ receptor antagonist might differentially precipitate anxiety-like behavior or reduce food intake in binge-fed sweet-fat diet animals.

Whereas unexpected withdrawal of a palatable diet can intrinsically increase anxiety-like behavior, access to palatable diets reportedly attenuates acute neuroendocrine responses to external stressors. For example, rats with ad libitum access to sucrose or lard in addition to standard chow showed reduced ACTH and corticosterone (CORT) responses to restraint stress [21-23]. Even brief twice-daily access to a sucrose or saccharin solution reduced ACTH and CORT restraint stress responses [24,25]. The ability of palatable diets to dampen the hypothalamic-pituitary-adrenal (HPA) axis stress response has been proposed to motivate both rodents and humans to consume "comfort food" under periods of stress [26]. In the present study, we therefore tested the hypothesis that a history of binge-like intake of a sweet fat diet alters basal or restraint-induced CORT levels. We also tested whether recovery to basal levels following restraint was facilitated if rats thereafter were allowed to binge.

\section{Materials and methods}

\subsection{Animals}

Adult Wistar rats $(n=90$, Charles River, Raleigh, NC) were group-housed in wire-topped plastic cages $\left(19 \times 10.5 \times 8\right.$ in.) in a temperature- $\left(22{ }^{\circ} \mathrm{C}\right)$ and humidity- $(60 \%)$ controlled vivarium with a 12:12 h reverse light cycle with lights off at 8:00 am or 10:00 am. Because bulimia and binge eating disorders are more prevalent in women than men [27], female rats were chosen as subjects. All procedures adhered to the guidelines for animal use provided by the National Institutes of Health Guide for the Care and Use of Laboratory Animals (NIH Publication number 85-23, revised 1996) and were approved by the Institutional Care and Use Committee of The Scripps Research Institute.

\subsection{Binge protocol 1 - diets and development of 10-min binge-like behavior}

Animals weighed 186-251 ( $M=219) \mathrm{g}$ at the start of experiments. Except as described below, all animals had access to water and standard rodent chow (Harlan Teklad LM-485, $3.1 \mathrm{kcal} / \mathrm{g}, 17 \% \mathrm{kcal}$ from fat, $58 \% \mathrm{kcal}$ from carbohydrates, $25 \% \mathrm{kcal}$ from protein, Harlan, Indianapolis, IN) ad libitum. To induce binge-like eating (Fig. 1), animals were transported daily to a testing room at dark cycle onset and placed individually into cages with wire mesh floors to permit monitoring of food spillage. Animals were then food-deprived for $2 \mathrm{~h}$, after which food was provided for a 10-min "binge" session in the testing room. The 10-min binge food consisted of either the standard rodent chow already described (chow group) or a nutritionally-complete high-fat diet (binge group: Bio-serv F06190, $4.1 \mathrm{kcal} / \mathrm{g}, 35 \% \mathrm{kcal}$ 
from fat, $46 \% \mathrm{kcal}$ from carbohydrates, $18 \% \mathrm{kcal}$ from protein, Bio-serv, Frenchtown, NJ, $\sim 85 \%$ of fat as saturated fat, $67 \%$ of carbohydrate as sucrose) that rats strongly prefer to chow (>99\% preference ratio when provided daily concurrent access for 1-h, Fekete and Zorrilla, unpublished observations). Diets were never concurrently presented to the same animals in the present study. Immediately after the 10-min binge, animals were removed from the testing room and returned to their home cages. Animals from a given home cage were assigned to the same diet groups, so home cage chow intake was estimated by dividing total intake by the number of rats. Degrees of freedom from subsequent statistical analyses were lowered accordingly. One binge animal that developed a malocclusion was dropped from all analyses, and its cagemate was not included in any outcome measure that involved home cage intake.

\subsection{Body composition}

Total fat mass and lean mass were determined after 6 weeks of the chow or binge diet access schedules using a whole body nuclear magnetic resonance machine (Echo-MRI-900, Echo Medical Systems, Houston, TX).

\subsection{Drugs}

The $\mathrm{CRF}_{1}$ antagonist R121919 [28] (generously provided by Kenner Rice, NIH) was solubilized first in $1 \mathrm{M} \mathrm{HCl}$ (10\% of final volume) then diluted in 2-hydroxypropyl-betacyclodextrin (Sigma-Aldrich, 20\% wt/vol final concentration) and titrated to $\mathrm{pH} 4.5$ with 1 $\mathrm{M} \mathrm{NaOH}$. The effects of R121919 treatment on intake during the 10-min binge session were determined by administering doses of $0,5,10$, and $20 \mathrm{mg} / \mathrm{kg}$ s.c. $60 \mathrm{~min}$ prior to the 10 -min binge in a within-subject Latin square design ( $n=7-8 /$ diet group). We have previously observed anxiolytic-like effects of R121919 on the elevated plus maze test and increases in progressive ratio responding for a less-preferred chow reinforcer using this same $60 \mathrm{~min}$ pretreatment interval at a dose of $20 \mathrm{mg} / \mathrm{kg}$ [12]. Progressive ratio effects were previously evident within the first 5 min of food access.

The $\mathrm{CB}_{1}$ antagonist surinabant [29] (SR147778, 5-(4-bromophenyl)-1- (2,4dichlorophenyl)- 4-ethyl- $N$-1-piperidinyl-1 $H$-pyrazole-3-carboxamide), an analog of rimonabant, was provided by Sanofi-Aventis (Paris, France) and suspended in an 18:1:1 mixture of $0.9 \%$ saline:ethanol:cremophor prior to injection. The effects of SR147778 treatment on intake during the 10-min binge session were determined by administering doses of $0,0.3,1,3$, and $10 \mathrm{mg} / \mathrm{kg}$ i.p. $30 \mathrm{~min}$ prior to the 10 -min binge in a within-subject Latin square design ( $n=8 /$ diet group). Effects of SR147778 treatment on plus-maze behavior were determined by administering a dose of $1 \mathrm{mg} / \mathrm{kg}$ or vehicle $30 \mathrm{~min}$ prior to the plusmaze test.

The effects of SR147778 treatment on 10-min intake of the sweet fat diet were also examined in a separate set $(n=8)$ of rats with no history of binge-like intake to help determine whether any differences across diet groups were in fact due to diet history (binge vs. chow) as opposed to the diet presented during the binge session itself (sweet fat vs. chow). Rats previously maintained on standard chow were allowed ad libitum access to the sweet fat diet in the home cage for $24 \mathrm{~h}$ prior to the start of drug treatments. As in Section 2.2 , rats were then transported daily to a separate testing room, food deprived for $2 \mathrm{~h}$, then provided with $10 \mathrm{~min}$ access to the same sweet fat diet. At the conclusion of this $10 \mathrm{~min}$ session, rats were returned to their home cages to continue consuming the sweet fat diet ad libitum. SR 147778 was administered at doses of 0, 0.3, 1, 3, and $10 \mathrm{mg} / \mathrm{kg}$ i.p. $30 \mathrm{~min}$ prior to the 10-min session in a within-subject Latin square design. 


\subsection{Estrous cycle synchronization}

To control for estrous cycle-related variability, estrous cycles were synchronized by administering (s.c.) two doses of $2 \mu \mathrm{g}$ each of the potent gonadotropin releasing hormone (GnRH) agonist [o-Trp ${ }^{6}$, Pro $\left.^{9}-\mathrm{NEt}\right]-\mathrm{GnRH}$ [30], generously provided by Dr. Jean Rivier (The Salk Institute, La Jolla, CA) to simulate the GnRH surge at proestrus. Rats received all drug treatments as well as the restraint stress and elevated plus-maze tests during diestrus.

\subsection{Elevated plus-maze}

Previously, we observed that rats receiving the present schedule of binge-like access, but to a high-sucrose diet, showed increased anxiety-like behavior on the elevated plus-maze when the diet was not available [7]. Therefore, we sought to determine whether increased anxietylike behavior also developed in relation to removal of the sweet high-fat diet. Elevated plusmaze tests were conducted on a black Plexiglas maze [31] that consisted of four arms with dimensions $50 \mathrm{~cm}$ long $\times 10 \mathrm{~cm}$ wide, two of which were enclosed by $40 \mathrm{~cm}$ high walls (closed arms), and two of which had $0.5 \mathrm{~cm}$ ledges along the sides (open arms). Each animal received a 5-min session on the maze following a minimum of $90 \mathrm{~min}$ of habituation in an adjacent room. Plus-maze testing was performed in a dimly-illuminated room $(\sim 3$ lux on open arms) during the first half of the dark cycle. Sessions were recorded for subsequent treatment-naïve scoring of time spent on the open vs. closed arms and the number of entries into each arm.

\subsubsection{Spontaneous and precipitated withdrawal from binge-like sweet fat diet} intake-To determine whether rats with a history of binge-like sweet fat diet intake showed increased spontaneous anxiety-like behavior, rats $(n=48)$ were tested on the elevated plusmaze during the 6th week of exposure to the chow or binge diet access schedules, approximately $24 \mathrm{~h}$ after the previous 10 -min binge session. To determine whether anxiogenic-like effects could be precipitated in binge animals by a $\mathrm{CB}_{1}$ antagonist, a class of compounds known to both reduce food intake [32] and to increase anxiety-like behavior [33] and which can precipitate withdrawal-like signs in cannabinoid-dependent animals [34], rats received either SR147778 (1.0 mg/kg, i.p.) or vehicle $30 \mathrm{~min}$ prior to being placed on the maze. The dose of SR147778 was sufficient to reduce food intake in both binge and chow rats (Fig. 4). No food deprivation period or 10-min binge session was given on plus-maze test days.

2.6.2. Plus-maze behavior following pellet priming-To determine whether a priming dose of the rats' respective binge foods would acutely alter anxiety-like behavior, a separate cohort of animals $(n=16)$ was tested on the elevated plus-maze at the end of the 10th week of exposure to the chow or binge diet access schedules. Rats were food deprived at dark onset and placed in the binge session cages, but they received only a small priming dose (three $45 \mathrm{mg}$ sweet fat diet pellets [only $0.6 \%$ of an average binge during the preceding week] or the equivalent weight of chow) of their 10-min binge session diet, without additional access to food. After the priming dose was consumed, rats were immediately placed on the elevated plus-maze in an adjacent room.

\subsection{Plasma corticosterone release after restraint stress}

To determine the effects of a history of binge-like intake of a sweet fat diet on the function of the hypothalamic-pituitary-adrenal axis, tail blood was collected from rats $(n=16)$ at 3 time points surrounding the 10-min binge session: 1) baseline conditions - prior to the 2-h food deprivation period, 2) stressed - immediately following $60 \mathrm{~min}$ of restraint stress in plastic semicylindrical restraint chambers that prevented the rat from freely moving or turning (stress onset immediately following the baseline bleed, $\sim 2 \mathrm{~h}$ prior to the binge 
session), and 3) post-binge recovery - 30 min following the conclusion of the binge session ( $100 \mathrm{~min}$ after the termination of the stressor). Tail blood was also collected on unstressed binge days to permit a within-subject comparison of plasma CORT levels at each time point. All tail blood samples were collected during weeks 13-15 of binge or chow diet access. Samples were collected over chilled tubes containing $10 \mu \mathrm{L}$ of $0.1 \mathrm{M}$ EDTA and centrifuged at $4{ }^{\circ} \mathrm{C}$ for $10 \mathrm{~min}$ at $1341 \mathrm{~g}$. The plasma fraction was stored at $-80{ }^{\circ} \mathrm{C}$ until analysis. CORT levels were quantified by radioimmunoassay with a commercially available kit per the manufacturer's instructions (MP Biomedicals, Solon, OH).

\subsection{Binge protocol 2 - individual housing with chow pre-presentation}

The 10-min binge protocol described in Section 2.2 was modified slightly from that used in our previous report of binge-like behavior associated with 10-min access to a high sucrose diet [7]. To address the alternative interpretation that procedural changes, rather than changes in diet composition, may have led to the different outcomes on anxiety-like behavior between studies, we performed an additional experiment that matched the previous protocol [7] precisely.

Binge-like intake was developed in a separate set of adult female Wistar rats $(n=16)$ as described in Section 2.2 with the following alterations. First, animals were singly rather than group-housed upon arrival and weighed 210-237 ( $M=224) \mathrm{g}$ at the start of experiments. Second, a pre-presentation of chow was included immediately following the 2-h food deprivation period, wherein both chow and binge rats were provided a feeder containing standard chow (Feeder 1) for $10 \mathrm{~min}$. At the conclusion of $10 \mathrm{~min}$, rats then received a second 10-min access period (Feeder 2) to either chow (chow group, $n=8$ ) or the sweet-fat diet (binge group, $n=8$ ) before being returned to their home cages. Third, no estrous cycle synchronization was performed. Fourth, the elevated plus-maze test was conducted on day 16 as described in Section 2.6, but in the absence of any drug or priming treatment.

To test the acute role of $\mathrm{CRF}_{1}$ in control of food intake under these conditions, the effects of R121919 treatment on 10-min intake and subsequent home cage chow intake were determined by administering doses of 0 or $20 \mathrm{mg} / \mathrm{kg}$ s.c. $60 \mathrm{~min}$ prior to the first $10-\mathrm{min}$ session in counterbalanced order in a within-subject design.

\subsection{Defensive withdrawal}

To determine whether anxiogenic-like effects could be detected after a longer duration of withdrawal from the sweet fat diet, rats from Section 2.8 also underwent a defensive withdrawal task on day 26 , approximately $48 \mathrm{~h}$ after their final 10 -min binge session. The testing arena was constructed of black foamed polyvinylchloride with dimensions of approximately $79 \times 79 \mathrm{~cm}$ with $50 \mathrm{~cm}$ high walls. A darkened withdrawal chamber (a 2-L Pyrex beaker shielded from outside light by wrapping in brown packing tape) was placed inside the arena with the opening $\sim 22 \mathrm{~cm}$ from one of the corners. Rats were habituated to an anteroom outside of the testing room for a minimum of $60 \mathrm{~min}$. After habituation, rats were placed individually into the withdrawal chamber, oriented facing the back, and allowed to freely explore the arena for 10 min under bright room light ( 250 lx on open field). Sessions were videorecorded for subsequent scoring of latency to emerge from the withdrawal chamber, withdrawals into the chamber, total time spent in the chamber, and time spent in the chamber per withdrawal by two reliable, treatment-naïve raters (intraclass correlation coefficients $>0.99$ for all outcome measures [35]).

\subsection{Statistical analysis}

Intake during the 10-min binge and the intervening home cage periods was analyzed by twoway repeated measures analyses of variance (ANOVA) with diet access group (chow or 
binge) as a between-subjects factor and day as a within-subjects factor. Pairwise comparisons between chow and binge groups on specific days (Fig. 2) were obtained with Student's $t$-test. Ten-min intake following R121919 or SR147778 pretreatment was analyzed by two-way repeated measures ANOVA with diet access group as a between-subjects factor and dose as a within-subjects factor. Ten-min intake in the ad libitum sweet fat-fed group was analyzed by one-way repeated measures ANOVA with dose as a within-subjects factor. Linear contrast ANOVAs were used to identify monophasic dose-responsive effects, as defined by a log-linear dose-response function [36]. Stability of individual differences in 10-min binge session intake across the 6-week study period was assessed by calculating two-way, random effect intraclass correlations of consistency agreement [35]. Total cumulative intake, body weight gain, and feed efficiency during the 6-week study period, as well as final fat mass and lean mass, were analyzed with Student's $t$-test.

For the spontaneous and $\mathrm{CB}_{1}$-antagonist precipitated testing in the elevated plus maze, percentage of time spent on or entries into the open arms (inverse measures of anxiety-like behavior) and total arm entries were analyzed by two-way ANOVA with diet access group and drug treatment (vehicle or SR147778) as between-subjects factors. For the food-primed elevated plus-maze test and untreated plus-maze test, differences between chow and binge groups on the same dependent measures were compared with Student's $t$-test. Two animals in the binge group were removed from the analysis of the food-primed plus-maze test - one for failing to consume any of the priming pellets and one that was determined to be an outlier for total entries and latency to consume the food prime by deviating more than five standard deviations from the jackknifed group mean.

For defensive withdrawal testing, latency to emerge from the withdrawal chamber, number of withdrawals into the chamber, total time spent in the withdrawal chamber, and time spent in the chamber per withdrawal were analyzed with Student's $t$-test.

Plasma CORT levels following restraint stress were analyzed by three-way repeated measures ANOVA with diet access group as a between-subjects factor and stress condition (stressed or unstressed) and timepoint (baseline, post-stress, post-binge) as within-subjects factors. Intake during the 10-min binge following 60 -min restraint was analyzed by two-way ANOVA with diet access group as a between-subjects factor and stress condition as a within-subjects factor. Higher order effects were interpreted by additional ANOVAs run separately for the interacting factors.

\section{Results}

\subsection{Binge protocol 1}

\subsubsection{Development of binge-like eating behavior and reduced home cage} chow intake-Rats in the binge group rapidly escalated their intake of the palatable highfat diet over consecutive 10-min binge sessions, with intake plateauing after 2-3 weeks (Fig. $2 \mathrm{a})$. By the third week of exposure, binge rats ate 5 -fold more calories than the chow rats during the 10 -min session $(M \pm$ SEM $26.9 \pm 1.3$ vs. $5.2 \pm 0.3 \mathrm{kcal}, t(61)=16.446, p<0.001$, Student's $t$-test), obtaining $38.0 \pm 1.3 \%$ of their total daily caloric intake during just $10 \mathrm{~min}$ compared to $7.8 \pm 0.4 \%$ in the chow group. Sweet fat diet intake did not further escalate between weeks 3-6 (week effect for binge group only $F(5,150)=43.37, p<0.001$; week $1<$ all subsequent weeks $p<0.001$, week $2<$ all subsequent weeks $p<0.01$, weeks $3-6 p$ 's not significant). Chow animals, in contrast, ate at a low, consistent rate during the 10-min session throughout the study (diet effect: $F(1,61)=299.18, p<0.001$; diet $\times$ day effect: $F(38$, 2318) $=19.86, p<0.001)$. 
The magnitude of intake during binge sessions showed individual differences across the entire 6-week observation period in both groups (chow group $I C C[2,35]$ consistency $=0.92$, binge group $I C C[2,35]$, consistency=.98), but the stable individual differences were notably greater from day-to-day within the binge group (binge group, ICC $[2,1]=.61 \mathrm{vs.} \mathrm{chow} \mathrm{group}$ $\operatorname{ICC}[2,1]=0.25)$.

When returned to their home cages, binge rats reduced their chow intake during the interval between daily 10-min binges. Chow hypophagia became more pronounced across time (diet effect: $F(1,21)=101.08, p<0.001$; diet $\times$ day effect: $F(36,756)=3.38, p=0.001)$.

Overall, over 6 weeks, total energy intake of binge rats was significantly, but only slightly (5.4\%), greater than that of chow rats (Fig. 2 c, $2723.4 \pm 54.6$ vs. $2584 \pm 33.4 \mathrm{kcal}, t(60)=2.21$, $p<0.05)$. Self-selected overall macronutrient intake in binge rats consisted of $23.6 \pm 0.2 \%$ $\mathrm{kcal}$ from fat, $53.8 \pm 0.1 \%$ from carbohydrate, and $22.5 \pm 0.1 \% \mathrm{kcal}$ from protein vs. the respective 17,58 and $25 \%$ proportions of chow rats.

\subsubsection{Excess weight gain and adiposity in rats with a history of binge-like,} sweet fat diet intake-Binge rats gained more weight across 6 weeks than did chow controls (Table $1, t(61)=2.57, p<0.05$ ). This weight gain reflected a selective increase in fat mass $(t(61)=2.91, p<0.01)$, rather than lean mass $(t(61)=0.71, \mathrm{~ns})$. Further, excess weight gain was not completely accounted for by the excess caloric intake, because feed efficiency also was significantly $(12.7 \%)$ greater in binge rats $(23.9 \pm 0.8$ vs. $21.2 \pm 1.0 \mathrm{mg}$ weight gained per kcal consumed, $t(60)=2.16, p<0.05)$.

\subsubsection{Pretreatment with a $\mathrm{CB}_{1}$, but not $\mathrm{CRF}_{1}$, antagonist reduces binge-like intake-To determine whether $\mathrm{CRF}_{1}$ receptors help maintain binge-like intake of the} sweet-fat diet, rats were pretreated with the $\mathrm{CRF}_{1}$ antagonist R121919. R121919 at doses up to $20 \mathrm{mg} / \mathrm{kg}$ had no effect on 10-min intake of either chow or the palatable high-fat diet (Fig. $3 \mathrm{a}$, b; no dose effect $F(3,39)=0.75$; no dosexdiet effect $F(3,39)=0.86$; $p$ 's $>0.4)$. These negative results contrast with our previous finding that $20 \mathrm{mg} / \mathrm{kg}$ of R 121919 reduced intake of a palatable, high-sucrose diet upon renewed access in diet-cycled rats [12].

In contrast, pretreatment with the $\mathrm{CB}_{1}$ antagonist SR147778 dose-dependently reduced 10min binge session intake in both chow and binge groups (Fig. 3c,d; dose effect $F(4,56)=25.298, p<0.001$; linear contrast effect of dose $F(1,14)=128.69, p<0.001)$. SR147778 had greater anorectic potency in the chow rats than binge rats (dosexdiet effect $F(4,56)=5.387 ; p<0.01 ;$ minimum effective dose $0.3 \mathrm{mg} / \mathrm{kg}$ in chow vs. $1.0 \mathrm{mg} / \mathrm{kg}$ in binge) and also produced greater maximal suppression of intake in chow $(8.2 \% \pm 3.7$ of vehicle intake) than binge rats $(41.9 \% \pm 6.7$ of vehicle intake).

In rats provided ad libitum sweet fat diet access, SR147778 also dose-dependently reduced 10-min intake of the sweet fat diet (Fig. 3e; dose effect $F(4,28)=9.94, p<0.001$; linear contrast effect of dose $F(1,7)=29.5, p<0.01)$. Maximal suppression of intake at the highest dose of $10 \mathrm{mg} / \mathrm{kg}(6.3 \pm 6.0 \%$ of vehicle intake) resembled that seen in chow rather than binge rats (Fig. $3 \mathrm{f}, t(14)=3.98, p<0.01$ ad lib sweet-fat vs. binge).

\subsubsection{Elevated plus-maze behavior is altered by a priming dose of sweet fat diet, but not binge-like diet history alone-To determine whether anxiety-like} behavior increased in binge rats when the sweet fat diet was not available, rats were tested on the elevated plus-maze $\sim 24 \mathrm{~h}$ after a 10-min binge. Withdrawal $(24 \mathrm{~h})$ from the high-fat diet did not enhance anxiety-like behavior in the binge animals, as measured by the $\%$ of arm time spent on (Fig. 4a, $F(1,43)=0.40$, ns) or entries into (Fig. $4 \mathrm{~b}, F(1,43)=0.49$, ns) the open arms of the maze. Pretreatment with an effective anorectic dose of SR147778 (1.0 mg/ 
kg i.p.) in an attempt to "precipitate" withdrawal also had no effect on the \% of arm time spent on or entries into the open arms (Fig. 4a-b, $F(1,43)=0.65$ and 0.19 , respectively, not significant). Anxiety-like behavior did not correlate with 10-min binge intake in chow or binge rats under either vehicle or SR147778-treated conditions (all $r^{2} \mathrm{~s}<0.5$, ns). Locomotor activity, as indicated by total arm entries, also did not differ between chow and binge groups or as a function of SR147778 treatment (Fig. $4 \mathrm{c}, F(1,43)=0.30$ and 0.49 , respectively, ns).

A priming 'dose' of the rats' respective binge diet immediately before the plus-maze test also did not elicit differences in anxiety-like behavior between the diet groups, as measured by the \% time spent on or entries into the open arms (Fig. 4a-b, $t(12)=0.60$ and 0.61 , respectively, ns). However, pellet priming did increase the overall locomotor activity, as indicated by more total arm entries in the binge relative to the chow group (Fig. 4c, $t(12)=3.44, p<0.01)$. Priming pellets were consumed more rapidly by the binge group than the chow group $(18.8 \pm 1.7 \mathrm{~s}$ vs. $55.4 \pm 12.3 \mathrm{~s}, t(12)=2.54, p<0.05)$.

\subsubsection{HPA-axis reactivity to restraint stress and binge-like sweet fat diet} intake-Restraint stress (60 min) significantly increased CORT levels by $\sim 2-3$-fold in both binge and chow rats, with recovery of CORT to basal levels by the post-binge timepoint (Table 2; stress $\times$ time point: $F(2,26)=5.02, p<0.05)$. Binge and chow rats did not differ from one another, at the baseline, stressed, or recovery time points under either unstressed or restraint conditions (no effect of diet: $F(1,13)=0.001$, ns, no interactions involving diet, all

$p$ ' $>>0.6$ ). Average basal CORT levels across stressed and unstressed days also did not differ between diet groups ( $205 \pm 39 \mathrm{ng} / \mathrm{mL}$ for chow vs. $247 \pm 26$ for binge rats, ns). Although restraint was sufficient to increase CORT levels markedly, it did not alter intake during the 10 -min period in either diet group (no effect of stress: $F(1,13)=1.16$, ns).

\subsection{Binge protocol 2}

\subsubsection{Single housing conditions and chow pre-presentation does not alter} binge-like intake-To determine whether changes in housing conditions or feeder presentation relative to our previous report [7] significantly impacted the development of binge-like behavior or weight gain, singly housed rats were assigned to chow or binge groups and provided with two consecutive 10 min feeding sessions: the first feeder contained standard chow regardless of diet group, whereas the second feeder contained either chow (chow group) or the sweet fat diet (binge group). As observed previously with a high-sucrose diet [7], binge rats suppressed their intake from the 1st feeder relative to chow rats $(F(1,14)=17.01, p<0.01$; Fig. 5a), but rapidly escalated their intake of the sweet fat diet from the 2 nd feeder at levels similar to those seen in group-housed rats of protocol 1 with only a single feeder presentation (Fig. 5b). This escalation, as before, was not observed in chow rats (diet effect: $F(1,14)=116.4, p<0.001$; diet $\times$ day effect: $F(22,308)=9.50 ; p<0.001$ ).

When returned to their home cages, binge rats again reduced their chow intake during the interval between daily 10-min binges (Fig. $5 \mathrm{c}$ ). As with protocol 1, chow hypophagia again became more pronounced across time (diet effect: $F(1,14)=22.2, p<0.001$; diet $\times$ day effect: $F(21,294)=2.80, p<0.001)$. Total energy intake over the 24-day study period was also significantly greater in binge rats than in chow rats (Fig. $5 \mathrm{~d}, 1897.5 \pm 41.7$ vs. $1668.0 \pm 49.2$ $\mathrm{kcal}, t(14)=3.56, p<0.01)$; this overall caloric difference was greater than that seen in grouphoused rats of protocol 1 despite the shorter study period (13.8 $\pm 2.5 \%$ vs. $5.4 \pm 2.1 \%$ $t(18.3)=2.55, p<0.05$, Welsh's $t$-test). Binge rats also gained more weight over the study period than chow controls $(41.9 \pm 2.8$ vs. $28.5 \pm 2.0 \mathrm{~g} ; t(14)=3.91, p<0.01)$ and had greater feed efficiency ( $22.0 \pm 1.2 \mathrm{vs} 17.2 \pm 1.2 \mathrm{mg}$ weight gained per kcal consumed; $t(14)=2.88$, $p<0.05)$. 
3.2.2. Lack of effects of $\mathrm{CRF}_{1}$ antagonist treatment on 10-min binge-like intake

-The procedural differences of protocol 2 (isolation housing, chow pre-presentation) did not alter the lack of effect of R121919 administration on binge-like intake of the sweet fat diet. R121919 at $20 \mathrm{mg} / \mathrm{kg}$ did not affect 10-min intake from the 1st feeder (Fig. 6a, no drug effect $F(1,14)=0.17, p=\mathrm{ns}$; no drug $\times$ diet effect $F(1,14)=0.01, p=$ ns) or from the 2 nd feeder in either chow or binge groups (Fig. $6 \mathrm{~b}$, no drug effect $F(1,14)=0.08$, $p=$ ns, no drug $\times$ diet effect $F(1,14)=1.01, p=n s)$. Further, R121919 treatment did not significantly affect home cage intake in either diet group (Fig. $6 c$, no drug effect $F(1.14)=2.18, p=$ ns; no drug $\times$ diet effect $F(1,14)=0.92, p=\mathrm{ns})$.

\subsubsection{Lack of anxiogenic-like behavior during withdrawal from 10-min binge-} like intake-Similarly, the procedural differences of protocol 2 did not lead to increased anxiety-like behavior in rats withdrawn from daily 10-min binge access. In the elevated plus maze (Fig. 6c), a history of binge-like intake did not alter $\%$ time spent on $(t(14)=0.36$, $p=\mathrm{ns})$ the open arms of the maze, $\%$ entries into the open arms $(t(14)=0.32, p=\mathrm{ns})$, or total arm entries $(t(14)=0.79, p=n s) 24 \mathrm{~h}$ following the previous binge. Further, neither $\%$ time spent on the open arms nor $\%$ entries in the open arms correlated with 10-min intake from either feeder in binge rats (all $r^{\prime} \mathrm{s}<0.6$, ns). There was a trend towards a correlation between reduced open arm time and increased intake from the 2 nd feeder in chow rats only, which did not reach significance $(r=627, p=0.10)$.

To determine whether an anxiety-like state might become apparent at a later timepoint in sweet-fat withdrawn rats, we conducted a defensive withdrawal test at $48 \mathrm{~h}$, rather than $24 \mathrm{~h}$, after the final 10-min binge session. In opposition to the hypothesis of increased anxiety-like behavior during withdrawal, rats with a history of binge-like sweet fat diet intake emerged from the withdrawal chamber more rapidly than did chow rats (Fig. $6 \mathrm{~d}, t(14)=2.52, p<0.05$ ), an anxiolytic-like effect. Non-significant trends for anxiolytic-like effects also were seen for binge rats withdrawing less frequently into the withdrawal chamber $(t(14)=1.86, p=.09)$ and spending less total time in the withdrawal chamber $(t(14)=1.75, p=0.10)$. No group differences were seen in the time spent in the chamber per withdrawal $(t(14)=.67, p=\mathrm{ns})$.

\section{Discussion}

The present study finds that daily, but highly limited (10 min), access to a sweet fat diet leads to binge-like intake, excess weight gain, and increased adiposity, without signs of a stress-like state upon withdrawal of the palatable diet. At $24 \mathrm{~h}$ after their most recent binge, rats with a history of binge-like sweet fat diet intake did not show increased anxiety-like behavior on the elevated plus-maze under spontaneous, binge-food primed or $\mathrm{CB}_{1^{-}}$ antagonist treated conditions. Binge history rats also did not show altered basal or restraintinduced circulating CORT levels, indicating normal adrenocortical responses to stress. Further, binge-like intake was unaffected by pretreatment with a $\mathrm{CRF}_{1}$ receptor antagonist, which reduces excess intake of rats withdrawn from a high sucrose diet [12], ethanol [3741], opiates [42], nicotine [43], or cocaine [44] in models of addiction. Instead, binge history rats showed locomotor activation in response to a sweet-fat food prime and reduced their binge-like intake in response to a selective $\mathrm{CB}_{1}$ antagonist, albeit less potently than did chow controls. Anticipatory negative contrast did develop when rats were provided with a feeder of less-preferred chow immediately prior to the 10-min sweet-fat binge, similar to the reduced acceptance of chow reported for a high sucrose diet [7]. This anticipatory negative contrast did not, however, appear to require concurrent withdrawal-based anxiety-like behavior. Indeed, with a longer duration of withdrawal ( $48 \mathrm{~h})$, sweet-fat binge history rats actually showed anxiolytic-like effects on a defensive withdrawal task. The collective results from this novel binge eating model contrast with reports of increased anxiety-like behavior and opiate-like withdrawal signs upon withdrawal of diets high in sugar $[2,7,11,12]$ and add 
to a growing literature finding mild or nonexistent withdrawal-like effects for high fat or sweet fat diets $[15,45]$.

Both limited access sweet-fat diet protocols utilized in this study produced similar degrees of binge-like intake and chow hypophagia as we previously observed in female rats receiving the same schedule of access to a high sucrose diet [7]. In the protocol matched precisely to our previous report, adverse metabolic effects of increased weight gain and feed efficiency were also comparable to animals with binge-like sucrose diet access. Yet, here, unlike with the high sucrose diet, increased anxiety-like behavior was not seen. Exactly which features of the high fat vs. high sugar diets yield different withdrawal-like outcomes remain to be determined. While differences in withdrawal-like signs might relate to general physiochemical properties of sugars vs. fats, they may also result from correlated, but not immutable, properties of the macronutrients. For example, although both diets were highly preferred to chow, perhaps the high sucrose diets studied yielded a more intense hedonic value than did the high fat diets. Consistent with this possibility, non-deprived rats showed greater acceptance of or preference for non-nutritive sweet tastants vs. non-nutritive 'fatty' tastants in previous studies [46,47], suggesting greater sweet vs. fat oral reward. Moreover, intra-gastric self-infusions of fats were less effective than iso-caloric self-infusion of sugars in producing conditioned solution intake [48] or flavor preferences [49-51] in rats, suggesting greater post-oral reward of sugar than fat under those test conditions. However, studies in C57BL/6J mice [52,53] have found comparable post-oral rewarding effects of fats vs. sweets, indicating that any macronutrient-associated differences in hedonic intensity are not absolute. One of the few findings of withdrawal-like responses following high-fat diet withdrawal involved altered open field behavior in mice withdrawn from access to a high fat diet that the mice strongly preferred to a high sugar (35\% sucrose) diet [14]. In this case, the less-preferred high sugar diet did not elicit withdrawal-like behavioral outcomes, consistent with the above interpretation that greater initial hedonic effects lead to more severe negative emotional effects upon withdrawal.

Another potentially key difference between fats and simple sugars concerns differences in their kinetics of digestion, absorption and clearance. Dietary simple sugars like glucose, sucrose and maltose, after rapid intestinal digestion and absorption, yield rapid spikes in blood glucose. The pronounced elevations strongly drive insulin secretion leading to similarly rapid glucose clearance. In contrast, dietary fat must be digested and absorbed in a much lengthier process that requires emulsification, hydrolysis to fatty acids, micelle aggregation, intestinal conversion to triglycerides for incorporation into chylomicrons and, ultimately, transport via the lymphatic system to blood circulation. Reflecting this protracted digestion and absorption process, post-oral rewarding effects of dietary fat in the mouse are later in onset and more gradual and sustained in magnitude than those of simple sugars [52]. By analogy, perhaps, a given unit dose of cocaine is less reinforcing when infused over a delayed or longer interval [54-58] or via a less rapidly absorbed route [59]. Furthermore, several substances of abuse, such as benzodiazepines, have rebound anxiety withdrawal potential if they have shorter elimination half-lives [60]. Thus, the rapid digestion, absorption, and clearance of simple sugars may be more conducive to post-oral addictionlike processes than the protracted absorption of fat. Addition of fat to diets high in simple sugars slows gastric emptying and both delays and inhibits absorption of the dietary sugar [61-65]. This may explain why sugar-containing sweet fat diets do not reliably elicit withdrawal-like effects, despite having sugar contents similar to or even greater than sugar solutions or low-fat but sugar-rich foods [15] and supporting binges of comparable magnitude.

A defining feature of binges is their discrete, intermittent nature with bouts of intense intake separated by periods of abstinence or dietary restriction. The lack of increased anxiety-like 
behavior at the time that rats would otherwise initiate their next binge ( $24 \mathrm{~h}$ post-binge) suggests that under the present conditions, withdrawal "anxiety" did not acutely motivate binge intake of the high-fat diet in negative reinforcement fashion. Additional support for this interpretation comes from the inability of an anxiolytic-like dose $[66,67]$ of a $\mathrm{CRF}_{1}$ antagonist (R121919) to attenuate binge-like intake and the normal basal and restraintinduced HPA-axis responses to stress of binge rats. Furthermore, binge rats did not increase their intake of the sweet fat diet when challenged by restraint stress, unlike previous reports of stress triggering enhanced "comfort feeding" of palatable foods $[4,23,26]$. Although the aforementioned differences in fat vs. sugar digestion and absorption might suggest that a withdrawal-like state would occur later in sweet-fat binging animals, anxiety-like phenotypes on a defensive withdrawal task were still not observed in binge history rats even at $48 \mathrm{~h}$ after the last binge session. The major implication of sustained binge-like intake ( $40 \%$ of daily energy consumed within 10 min across months of access) without signs of increased anxiety-like behavior or stress reactivity upon withdrawal is that the primary factor driving binge intake of the sweet fat diet was not the relief from a negative emotional state, a key component of relapse in drug addiction, alcoholism, and high sugar diet consumption $[11,68]$. Instead, the binge intake may reflect ongoing appetitive, rewarding effects of the highly palatable food and/or learned, habitual responses. Our observation that a history of binge-like intake decreased latency to emerge from a protected withdrawal chamber may be a reflection of these ongoing appetitive effects.

A key trigger of binge eating is the initial sensory cues associated with the diet itself. In animal models, rats trained to lever press for palatable food pellets and then extinguished for this response will reinstate food-seeking (non-reinforced) behavior if primed with a single palatable food pellet $[69,70]$. A palatable food prime also can potentiate palatable food context-induced binging on chow [71]. In the present study, a taste of the binge food, which also can precipitate binges in humans [16], increased overall activity levels of binge rats in the plus-maze without altering their anxiety-like behavior. The locomotor activation may reflect arousal, anticipatory behavior, or foraging entrained to scheduled palatable food access [72-74] or a response analogous to frustrative non-reward [75,76] in binge rats, differences that were not present in the absence of the food prime. The results further support the hypothesis that binge foods acquire conditioned incentive motivating properties.

A second, not mutually exclusive interpretation of sustained binge-like behavior without accompanying anxiety is that the daily binges become compulsive learned behaviors or habits that are resistant to environmental factors and independent of energy need. Consistent with this possibility, rodents will endure adverse conditions such as a brightly lit arena [14] or environmental cues previously paired with foot shock [77] in order to obtain a palatable diet, suggesting the development of compulsive intake patterns despite mounting negative consequences. Data from the current study that support the hypothesis that the binge-like behavior was resistant to change include the marked day-to-day stability of individual differences in binge magnitude, the stability of the binge despite 1-h restraint or blood sampling, and the diminished potency and efficacy of SR147778, a CB 1 antagonist, to attenuate binge-like intake of the high-fat diet, as compared to chow. The latter finding is noteworthy because previous reports have suggested that $\mathrm{CB}_{1}$ antagonists preferentially target the intake of more palatable foods $[32,78,79]$ by reducing their acute hedonic value [80]. Accordingly, $\mathrm{CB}_{1}$ antagonists more effectively reduce ad libitum intake of palatable high-fat, than chow diets [[78], but see also [81]]. Indeed, we observed greater efficacy of a $\mathrm{CB}_{1}$ antagonist in reducing 10-min sweet fat diet intake when this diet was provided ad libitum in the home cage rather than solely during the 10-min binge. The relative resistance of the binge-like intake specifically to $\mathrm{CB}_{1}$ antagonist treatment suggests that acute food reward may be less important for maintaining binge-like eating, once established. However, the minimum effective dose that reduced 10-min intake was similar in binge and ad libitum 
sweet fat rats. An alternative possibility is thus that perhaps the more intense reward of the binge and its associated palatable diet requires a greater dose of $\mathrm{CB}_{1}$ antagonist to surmount endocannabinoid action.

\section{Conclusions}

Binge-like intake of a sweet fat diet under limited access conditions persists for weeks or months in the absence of a negative anxiety-like state upon sweet fat diet removal, suggesting that unique biological mechanisms may contribute preferentially to excessive intake of sugars vs. fats. The resilience of binge-like eating behavior to modification by either restraint stress or $\mathrm{CB}_{1}$ antagonists further suggests that learned, habitual, or cued intake of palatable foods may be of particular importance in sustaining the binge-like intake. Because the typical Western diet is comparable in fat proportions $(32-34 \%,[82])$ to the present sweet fat diet (35\%), clinical interventions to reduce binge intake of fat-containing "Western" foods may more effectively target aspects of cued intake or positive reinforcement, rather than negative reinforcement.

\section{Acknowledgments}

The authors thank Michael Arends for editorial assistance with the manuscript and Jean Kim and Daniel Le for technical assistance. Financial support for this work was provided by the Pearson Center for Alcoholism and Addiction Research, the Harold L Dorris Neurological Research Institute, and grants DK070118, DK076896, DA023680, DA026690, and 1T32NS061847 from the NIH. A portion of this work was supported by the Intramural Research Programs of the National Institute on Drug Abuse and National Institute on Alcohol Abuse and Alcoholism. The content is solely the responsibility of the authors and does not necessarily represent the official views of the National Institutes of Health. This is manuscript number 21675 from The Scripps Research Institute.

\section{References}

[1]. Allison S, Timmerman GM. Anatomy of a binge: food environment and characteristics of nonpurge binge episodes. Eat Behav. 2007; 8:31-8. [PubMed: 17174849]

[2]. Avena NM, Bocarsly ME, Rada P, Kim A, Hoebel BG. After daily bingeing on a sucrose solution, food deprivation induces anxiety and accumbens dopamine/acetylcholine imbalance. Physiol Behav. 2008; 94:309-15. [PubMed: 18325546]

[3]. Berner LA, Avena NM, Hoebel BG. Bingeing, self-restriction, and increased body weight in rats with limited access to a sweet-fat diet. Obesity (Silver Spring). 2008; 16:1998-2002. [PubMed: 19186326]

[4]. Boggiano MM, Chandler PC. Binge eating in rats produced by combining dieting with stress. Curr Protoc Neurosci. 2006; 36:9.23A.1-8.

[5]. Corwin RL, Wojnicki FH. Binge eating in rats with limited access to vegetable shortening. Curr Protoc Neurosci. 2006; 36:9.23B.1-11.

[6]. Wojnicki FH, Charny G, Corwin RL. Binge-type behavior in rats consuming trans-fat-free shortening. Physiol Behav. 2008; 94:627-9. [PubMed: 18499201]

[7]. Cottone P, Sabino V, Steardo L, Zorrilla EP. Opioid-dependent anticipatory negative contrast and binge-like eating in rats with limited access to highly preferred food. Neuropsychopharmacology. 2008; 33:524-35. [PubMed: 17443124]

[8]. DesMaisons, K. The sugar addict's total recovery program. Ballantine Books; 2002.

[9]. Dufty, W. Sugar blues. Grand Central Publishing; 1986.

[10]. Lustig RH, Schmidt LA, Brindis CD. Public health: the toxic truth about sugar. Nature. 2012; 482:27-9. [PubMed: 22297952]

[11]. Colantuoni C, Rada P, McCarthy J, Patten C, Avena NM, Chadeayne A, et al. Evidence that intermittent, excessive sugar intake causes endogenous opioid dependence. Obes Res. 2002; 10:478-88. [PubMed: 12055324] 
[12]. Cottone P, Sabino V, Roberto M, Bajo M, Pockros L, Frihauf JB, et al. CRF system recruitment mediates dark side of compulsive eating. Proc Natl Acad Sci U S A. 2009; 106:20016-20. [PubMed: 19901333]

[13]. Cottone P, Sabino V, Steardo L, Zorrilla EP. Consummatory, anxiety-related and metabolic adaptations in female rats with alternating access to preferred food. Psychoneuroendocrinology. 2009; 34:38-49. [PubMed: 18842344]

[14]. Teegarden SL, Bale TL. Decreases in dietary preference produce increased emotionality and risk for dietary relapse. Biol Psychiatry. 2007; 61:1021-9. [PubMed: 17207778]

[15]. Bocarsly ME, Berner LA, Hoebel BG, Avena NM. Rats that binge eat fat-rich food do not show somatic signs or anxiety associated with opiate-like withdrawal: implications for nutrient-specific food addiction behaviors. Physiol Behav. 2011; 104:865-72. [PubMed: 21635910]

[16]. Waters A, Hill A, Waller G. Internal and external antecedents of binge eating episodes in a group of women with bulimia nervosa. Int J Eat Disord. 2001; 29:17-22. [PubMed: 11135328]

[17]. Hagan MM, Chandler PC, Wauford PK, Rybak RJ, Oswald KD. The role of palatable food and hunger as trigger factors in an animal model of stress induced binge eating. Int J Eat Disord. 2003; 34:183-97. [PubMed: 12898554]

[18]. Timofeeva E, Baraboi ED, Poulin AM, Richard D. Palatable high-energy diet decreases the expression of cannabinoid type 1 receptor messenger RNA in specific brain regions in the rat. $\mathrm{J}$ Neuroendocrinol. 2009; 21:982-92. [PubMed: 19807847]

[19]. Izzo AA, Piscitelli F, Capasso R, Aviello G, Romano B, Borrelli F, et al. Peripheral endocannabinoid dysregulation in obesity: relation to intestinal motility and energy processing induced by food deprivation and re-feeding. Br J Pharmacol. 2009; 158:451-61. [PubMed: 19371345]

[20]. DiPatrizio NV, Simansky KJ. Activating parabrachial cannabinoid CB1 receptors selectively stimulates feeding of palatable foods in rats. J Neurosci. 2008; 28:9702-9. [PubMed: 18815256]

[21]. Foster MT, Warne JP, Ginsberg AB, Horneman HF, Pecoraro NC, Akana SF, et al. Palatable foods, stress, and energy stores sculpt corticotropin-releasing factor, adrenocorticotropin, and corticosterone concentrations after restraint. Endocrinology. 2009; 150:2325-33. [PubMed: 19106219]

[22]. la Fleur SE, Houshyar H, Roy M, Dallman MF. Choice of lard, but not total lard calories, damps adrenocorticotropin responses to restraint. Endocrinology. 2005; 146:2193-9. [PubMed: 15705773]

[23]. Pecoraro N, Reyes F, Gomez F, Bhargava A, Dallman MF. Chronic stress promotes palatable feeding, which reduces signs of stress: feedforward and feedback effects of chronic stress. Endocrinology. 2004; 145:3754-62. [PubMed: 15142987]

[24]. Ulrich-Lai YM, Christiansen AM, Ostrander MM, Jones AA, Jones KR, Choi DC, et al. Pleasurable behaviors reduce stress via brain reward pathways. Proc Natl Acad Sci U S A. 2010; 107:20529-34. [PubMed: 21059919]

[25]. Ulrich-Lai YM, Ostrander MM, Thomas IM, Packard BA, Furay AR, Dolgas CM, et al. Daily limited access to sweetened drink attenuates hypothalamic-pituitary-adrenocortical axis stress responses. Endocrinology. 2007; 148:1823-34. [PubMed: 17204558]

[26]. Dallman MF, Pecoraro N, Akana SF, La Fleur SE, Gomez F, Houshyar H, et al. Chronic stress and obesity: a new view of "comfort food". Proc Natl Acad Sci U S A. 2003; 100:11696-701. [PubMed: 12975524]

[27]. Hudson JI, Hiripi E, Pope HG Jr, Kessler RC. The prevalence and correlates of eating disorders in the National Comorbidity Survey Replication. Biol Psychiatry. 2007; 61:348-58. [PubMed: 16815322]

[28]. Chen C, Wilcoxen KM, Huang CQ, Xie YF, McCarthy JR, Webb TR, et al. Design of 2,5dimethyl-3-(6-dimethyl-4-methylpyridin-3-yl)-7-dipropylaminopyrazolo [1,5-a]py rimidine (NBI 30775/R121919) and structure-activity relationships of a series of potent and orally active corticotropin-releasing factor receptor antagonists. J Med Chem. 2004; 47:4787-98. [PubMed: 15341493]

[29]. Rinaldi-Carmona M, Barth F, Congy C, Martinez S, Oustric D, Perio A, et al. SR147778 [5-(4bromophenyl)-1-(2,4-dichlorophenyl)-4-ethyl-N-(1-piperidinyl)-1H-pyrazole-3 -carboxamide], a 
new potent and selective antagonist of the CB1 cannabinoid receptor: biochemical and pharmacological characterization. J Pharmacol Exp Ther. 2004; 310:905-14. [PubMed: 15131245]

[30]. Rivier J, Amoss M, Rivier C, Vale W. Synthetic luteinizing hormone releasing factor. Short chain analogs. J Med Chem. 1974; 17:230-3. [PubMed: 4588276]

[31]. Zorrilla EP, Valdez GR, Nozulak J, Koob GF, Markou A. Effects of antalarmin, a CRF type 1 receptor antagonist, on anxiety-like behavior and motor activation in the rat. Brain Res. 2002; 952:188-99. [PubMed: 12376179]

[32]. Arnone M, Maruani J, Chaperon F, Thiebot MH, Poncelet M, Soubrie P, et al. Selective inhibition of sucrose and ethanol intake by SR 141716, an antagonist of central cannabinoid (CB1) receptors. Psychopharmacology (Berl). 1997; 132:104-6. [PubMed: 9272766]

[33]. Navarro M, Hernandez E, Munoz RM, del Arco I, Villanua MA, Carrera MR, et al. Acute administration of the CB1 cannabinoid receptor antagonist SR 141716A induces anxiety-like responses in the rat. Neuroreport. 1997; 8:491-6. [PubMed: 9080435]

[34]. Aceto MD, Scates SM, Lowe JA, Martin BR. Cannabinoid precipitated withdrawal by the selective cannabinoid receptor antagonist, SR 141716A. Eur J Pharmacol. 1995; 282:R1-2. [PubMed: 7498260]

[35]. Shrout PE, Fleiss JL. Intraclass correlations: uses in assessing rater reliability. Psychol Bull. 1979; 86:420-8. [PubMed: 18839484]

[36]. Rosner, B. Fundamentals of biostatistics. Duxbury Press; Boston, MA: 1995.

[37]. Sabino V, Cottone P, Koob GF, Steardo L, Lee MJ, Rice KC, et al. Dissociation between opioid and CRF1 antagonist sensitive drinking in Sardinian alcohol-preferring rats. Psychopharmacology (Berl). 2006; 189:175-86. [PubMed: 17047935]

[38]. Funk CK, Zorrilla EP, Lee MJ, Rice KC, Koob GF. Corticotropin-releasing factor 1 antagonists selectively reduce ethanol self-administration in ethanol-dependent rats. Biol Psychiatry. 2007; 61:78-86. [PubMed: 16876134]

[39]. Gilpin NW, Richardson HN, Koob GF. Effects of CRF1-receptor and opioid-receptor antagonists on dependence-induced increases in alcohol drinking by alcohol-preferring $(\mathrm{P})$ rats. Alcohol Clin Exp Res. 2008; 32:1535-42. [PubMed: 18631323]

[40]. Richardson HN, Zhao Y, Fekete EM, Funk CK, Wirsching P, Janda KD, et al. MPZP: a novel small molecule corticotropin-releasing factor type 1 receptor (CRF1) antagonist. Pharmacol Biochem Behav. 2008; 88:497-510. [PubMed: 18031798]

[41]. Gehlert DR, Cippitelli A, Thorsell A, Le AD, Hipskind PA, Hamdouchi C, et al. 3-(4-Chloro-2morpholin-4-yl-thiazol-5-yl)-8-(1-ethylpropyl)-2,6-dimethyl-imidazo[1,2-b]pyridazine: a novel brain-penetrant, orally available corticotropin-releasing factor receptor 1 antagonist with efficacy in animal models of alcoholism. J Neurosci. 2007; 27:2718-26. [PubMed: 17344409]

[42]. Greenwell TN, Funk CK, Cottone P, Richardson HN, Chen SA, Rice KC, et al. Corticotropinreleasing factor-1 receptor antagonists decrease heroin self-administration in long- but not shortaccess rats. Addict Biol. 2009; 14:130-43. [PubMed: 19291009]

[43]. George O, Ghozland S, Azar MR, Cottone P, Zorrilla EP, Parsons LH, et al. CRF-CRF1 system activation mediates withdrawal-induced increases in nicotine self-administration in nicotinedependent rats. Proc Natl Acad Sci U S A. 2007; 104:17198-203. [PubMed: 17921249]

[44]. Specio SE, Wee S, O’Dell LE, Boutrel B, Zorrilla EP, Koob GF. CRF(1) receptor antagonists attenuate escalated cocaine self-administration in rats. Psychopharmacology (Berl). 2008; 196:473-82. [PubMed: 17965976]

[45]. Avena NM, Rada P, Hoebel BG. Sugar and fat bingeing have notable differences in addictivelike behavior. J Nutr. 2009; 139:623-8. [PubMed: 19176748]

[46]. Ackroff K, Vigorito M, Sclafani A. Fat appetite in rats: the response of infant and adult rats to nutritive and non-nutritive oil emulsions. Appetite. 1990; 15:171-88. [PubMed: 2281948]

[47]. Lucas F, Sclafani A. Food deprivation increases the rat's preference for a fatty flavor over a sweet taste. Chem Senses. 1996; 21:169-79. [PubMed: 8670695]

[48]. Ramirez I. Stimulation of fluid intake by nutrients: oil is less effective than carbohydrate. Am J Physiol. 1997; 272:R289-93. [PubMed: 9039020] 
[49]. Ackroff K, Dym C, Yiin YM, Sclafani A. Rapid acquisition of conditioned flavor preferences in rats. Physiol Behav. 2009; 97:406-13. [PubMed: 19303888]

[50]. Lucas F, Sclafani A. Differential reinforcing and satiating effects of intragastric fat and carbohydrate infusions in rats. Physiol Behav. 1999; 66:381-8. [PubMed: 10357426]

[51]. Tracy AL, Phillips RJ, Chi MM, Powley TL, Davidson TL. The gastrointestinal tract "tastes" nutrients: evidence from the intestinal taste aversion paradigm. Am J Physiol Regul Integr Comp Physiol. 2004; 287:R1086-100. [PubMed: 15256365]

[52]. Zukerman S, Ackroff K, Sclafani A. Rapid post-oral stimulation of intake and flavor conditioning by glucose and fat in the mouse. Am J Physiol Regul Integr Comp Physiol. 2011; 301:R1635-47. [PubMed: 21975648]

[53]. Sclafani A, Glendinning JI. Sugar and fat conditioned flavor preferences in C57BL/6J and 129 mice: oral and postoral interactions. Am J Physiol Regul Integr Comp Physiol. 2005; 289:R71220. [PubMed: 15845881]

[54]. Balster RL, Schuster CR. Fixed-interval schedule of cocaine reinforcement: effect of dose and infusion duration. J Exp Anal Behav. 1973; 20:119-29. [PubMed: 4197505]

[55]. Corrigall WA, Coen KM. Fixed-interval schedules for drug self-administration in the rat. Psychopharmacology (Berl). 1989; 99:136-9. [PubMed: 2506599]

[56]. Wakabayashi KT, Weiss MJ, Pickup KN, Robinson TE. Rats markedly escalate their intake and show a persistent susceptibility to reinstatement only when cocaine is injected rapidly. $\mathrm{J}$ Neurosci. 2010; 30:11346-55. [PubMed: 20739555]

[57]. Schindler CW, Panlilio LV, Thorndike EB. Effect of rate of delivery of intravenous cocaine on self-administration in rats. Pharmacol Biochem Behav. 2009; 93:375-81. [PubMed: 19464316]

[58]. Liu Y, Roberts DC, Morgan D. Sensitization of the reinforcing effects of self-administered cocaine in rats: effects of dose and intravenous injection speed. Eur J Neurosci. 2005; 22:195200. [PubMed: 16029209]

[59]. Volkow ND, Wang GJ, Fischman MW, Foltin R, Fowler JS, Franceschi D, et al. Effects of route of administration on cocaine induced dopamine transporter blockade in the human brain. Life Sci. 2000; 67:1507-15. [PubMed: 10983846]

[60]. Chouinard G. Issues in the clinical use of benzodiazepines: potency, withdrawal, and rebound. J Clin Psychiatry. 2004; 65(Suppl. 5):7-12. [PubMed: 15078112]

[61]. Lodefalk M, Aman J, Bang P. Effects of fat supplementation on glycaemic response and gastric emptying in adolescents with type 1 diabetes. Diabet Med. 2008; 25:1030-5. [PubMed: 19183308]

[62]. Marciani L, Wickham M, Singh G, Bush D, Pick B, Cox E, et al. Enhancement of intragastric acid stability of a fat emulsion meal delays gastric emptying and increases cholecystokinin release and gallbladder contraction. Am J Physiol Gastrointest Liver Physiol. 2007; 292:G160713. [PubMed: 17332474]

[63]. Gentilcore D, Chaikomin R, Jones KL, Russo A, Feinle-Bisset C, Wishart JM, et al. Effects of fat on gastric emptying of and the glycemic, insulin, and incretin responses to a carbohydrate meal in type 2 diabetes. J Clin Endocrinol Metab. 2006; 91:2062-7. [PubMed: 16537685]

[64]. Welch IM, Bruce C, Hill SE, Read NW. Duodenal and ileal lipid suppresses post-prandial blood glucose and insulin responses in man: possible implications for the dietary management of diabetes mellitus. Clin Sci (Lond). 1987; 72:209-16. [PubMed: 3545642]

[65]. Horowitz M, Jones KL, Rayner CK, Read NW. 'Gastric' hypoglycaemia-an important concept in diabetes management. Neurogastroenterol Motil. 2006; 18:405-7. [PubMed: 16700718]

[66]. Gutman DA, Owens MJ, Skelton KH, Thrivikraman KV, Nemeroff CB. The corticotropinreleasing factor1 receptor antagonist R121919 attenuates the behavioral and endocrine responses to stress. J Pharmacol Exp Ther. 2003; 304:874-80. [PubMed: 12538845]

[67]. Keck ME, Welt T, Wigger A, Renner U, Engelmann M, Holsboer F, et al. The anxiolytic effect of the CRH(1) receptor antagonist R121919 depends on innate emotionality in rats. Eur J Neurosci. 2001; 13:373-80. [PubMed: 11168542]

[68]. Koob GF, Le Moal M. Plasticity of reward neurocircuitry and the 'dark side' of drug addiction. Nat Neurosci. 2005; 8:1442-4. [PubMed: 16251985] 
[69]. Ghitza UE, Gray SM, Epstein DH, Rice KC, Shaham Y. The anxiogenic drug yohimbine reinstates palatable food seeking in a rat relapse model: a role of CRF1 receptors. Neuropsychopharmacology. 2006; 31:2188-96. [PubMed: 16341025]

[70]. Ghitza UE, Nair SG, Golden SA, Gray SM, Uejima JL, Bossert JM, et al. Peptide YY3-36 decreases reinstatement of high-fat food seeking during dieting in a rat relapse model. J Neurosci. 2007; 27:11522-32. [PubMed: 17959795]

[71]. Boggiano MM, Dorsey JR, Thomas JM, Murdaugh DL. The Pavlovian power of palatable food: lessons for weight-loss adherence from a new rodent model of cue-induced overeating. Int J Obes (Lond). 2009; 33:693-701. [PubMed: 19350040]

[72]. Mistlberger R, Rusak B. Palatable daily meals entrain anticipatory activity rhythms in freefeeding rats: dependence on meal size and nutrient content. Physiol Behav. 1987; 41:219-26. [PubMed: 3432379]

[73]. Mendoza J, Angeles-Castellanos M, Escobar C. Entrainment by a palatable meal induces foodanticipatory activity and c-Fos expression in reward-related areas of the brain. Neuroscience. 2005; 133:293-303. [PubMed: 15893651]

[74]. Mistlberger RE. Circadian food-anticipatory activity: formal models and physiological mechanisms. Neurosci Biobehav Rev. 1994; 18:171-95. [PubMed: 8058212]

[75]. Amsel A. The role of frustrative nonreward in noncontinuous reward situations. Psychol Bull. 1958; 55:102-19. [PubMed: 13527595]

[76]. Drobes DJ, Miller EJ, Hillman CH, Bradley MM, Cuthbert BN, Lang PJ. Food deprivation and emotional reactions to food cues: implications for eating disorders. Biol Psychol. 2001; 57:15377. [PubMed: 11454438]

[77]. Johnson PM, Kenny PJ. Dopamine D2 receptors in addiction-like reward dysfunction and compulsive eating in obese rats. Nat Neurosci. 2010; 13:635-41. [PubMed: 20348917]

[78]. Mathes CM, Ferrara M, Rowland NE. Cannabinoid-1 receptor antagonists reduce caloric intake by decreasing palatable diet selection in a novel dessert protocol in female rats. Am J Physiol Regul Integr Comp Physiol. 2008; 295:R67-75. [PubMed: 18448611]

[79]. Simiand J, Keane M, Keane PE, Soubrie P. SR 141716, a CB1 cannabinoid receptor antagonist, selectively reduces sweet food intake in marmoset. Behav Pharmacol. 1998; 9:179-81. [PubMed: 10065938]

[80]. Jarrett MM, Scantlebury J, Parker LA. Effect of delta9-tetrahydrocannabinol on quinine palatability and AM251 on sucrose and quinine palatability using the taste reactivity test. Physiol Behav. 2007; 90:425-30. [PubMed: 17118412]

[81]. Verty AN, McGregor IS, Mallet PE. Consumption of high carbohydrate, high fat, and normal chow is equally suppressed by a cannabinoid receptor antagonist in non-deprived rats. Neurosci Lett. 2004; 354:217-20. [PubMed: 14700735]

[82]. USDA. Data tables: results from USDA's 1994-96 continuing survey of food intakes by individuals and 1994-96 diet and health knowledge survey. 1999. 


\section{HIGHLIGHTS}

Binge-like eating develops in rats with 10-min daily access to a sweet fat diet.

- Sweet fat binging increases weight gain, adiposity, and feed efficiency.

- Binge magnitude is reduced by a $\mathrm{CB}_{1}$, but not $\mathrm{CRF}$, receptor antagonist.

- Neither anxiety-like behavior nor HPA axis activity is altered by binge history.

-Unlike sugar diets, sweet fat diets maintain binge-like intake without withdrawal. 


\begin{tabular}{|c|c|c|c|c|}
\hline Group & Lights on & \multicolumn{3}{|c|}{ Lights off } \\
\hline Chow & Chow ad libitum & 2hr deprivation & $\begin{array}{c}10 \mathrm{~min} \\
\text { Chow }\end{array}$ & Chow ad libitum \\
\hline Binge & Chow ad libitum & 2hr deprivation & $\begin{array}{c}10 \mathrm{~min} \\
\text { Sweet Fat }\end{array}$ & Chow ad libitum \\
\hline
\end{tabular}

Fig. 1.

Limited access protocol to promote binge-like intake of a sweet fat diet. Female Wistar rats were allowed to consume standard chow (Harlan Teklad LM-485, $3.1 \mathrm{kcal} / \mathrm{g}, 17 \%$ of kcal from fat) ad libitum in their home cages throughout the light cycle. At dark onset, all rats were transported to individual test cages and food deprived for $2 \mathrm{~h}$. Following the deprivation, animals received 10-min access either to the same standard chow (chow group) or a highly palatable sweet, high-fat diet (Bio-serv F06190, $4.1 \mathrm{kcal} / \mathrm{g}, 35 \% \mathrm{kcal}$ from fat, binge group). All rats were returned to their home cages following the 10-min binge. Diets were never presented concurrently to the same animal. 

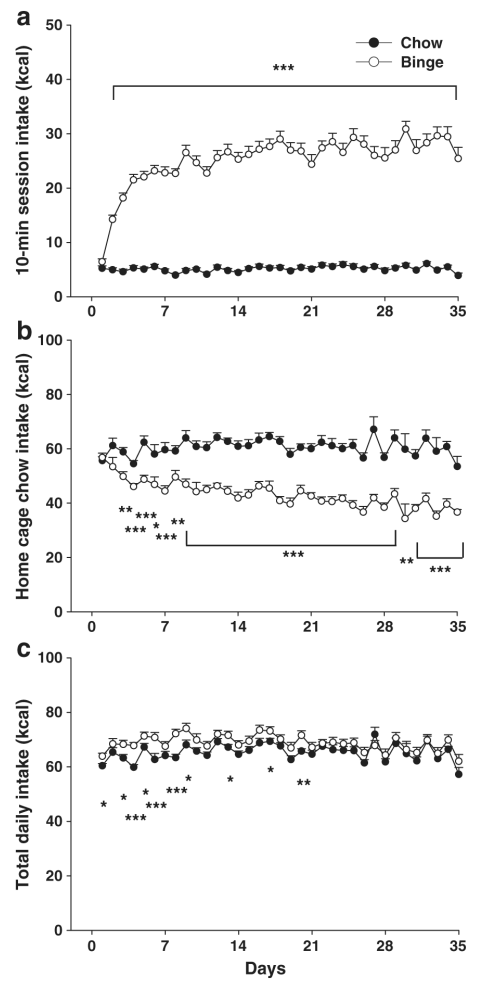

Fig. 2.

Binge-like intake of a sweet fat diet developed rapidly with daily exposure to a mere 10-min diet access following a 2-h food deprivation period. Data are expressed as $M \pm S E M$ in panel a) 10-min intake (kcal) of either standard chow (chow) or a highly palatable sweet fat diet (binge). Binge rats escalate 10-min intake across the first 3 weeks of exposure and plateau at a level of $\sim 40 \%$ total daily kcal intake during the 10-min binge. b) Ad libitum home cage intake of standard chow during the intervening time between binge sessions was decreased in binge rats. c) Total daily combined intake of both standard chow and the highly palatable diet. Binge rats consumed slightly more kcal cumulatively across the 6-week study period than chow rats. Differs from chow $* p<0.05, * * p<0.01$, and $* * * p<0.001$. 

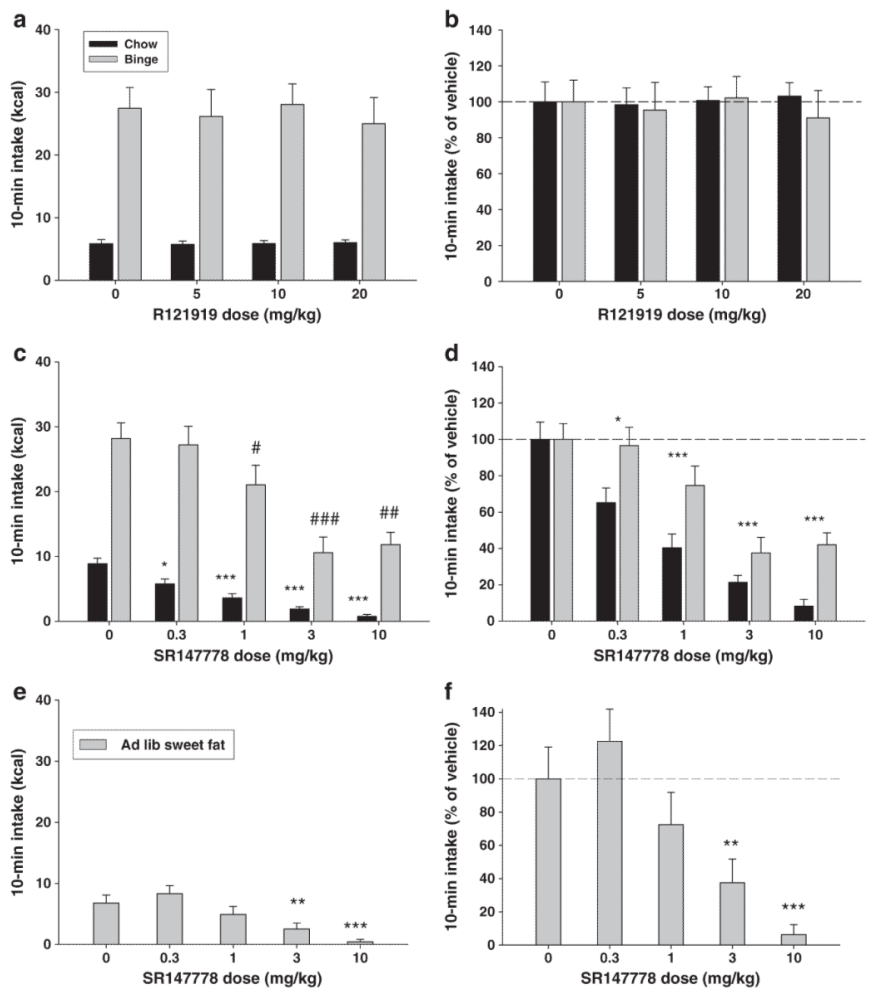

Fig. 3 .

Binge-like intake of a sweet fat diet was blocked by a $\mathrm{CB}_{1}$ receptor antagonist, but not by a $\mathrm{CRF}_{1}$ receptor antagonist. a, b) Pretreatment with the $\mathrm{CRF}_{1}$ antagonist R121919 did not impact intake of either sweet fat diet or standard chow during a daily 10-min binge as measured by raw kcal consumed (a) or \% of vehicle intake (b). c, d) Pretreatment with the $\mathrm{CB}_{1}$ antagonist SR147778, in contrast, dramatically reduced 10-min intake of sweet fat diet and standard chow (raw kcal, c; \% vehicle intake, d). e) Pretreatment with SR147778 also reduced 10-min intake of the sweet fat diet in rats with ad libitum access to the same sweet fat diet in their home cages. f) Maximal suppression at the highest dose mirrored the efficacy observed in chow, rather than binge rats. Differs from vehicle * $p<0.05, * * p<0.01$, and $* * * p<0.01$; \# differs from binge/veh $p<0.05$. 

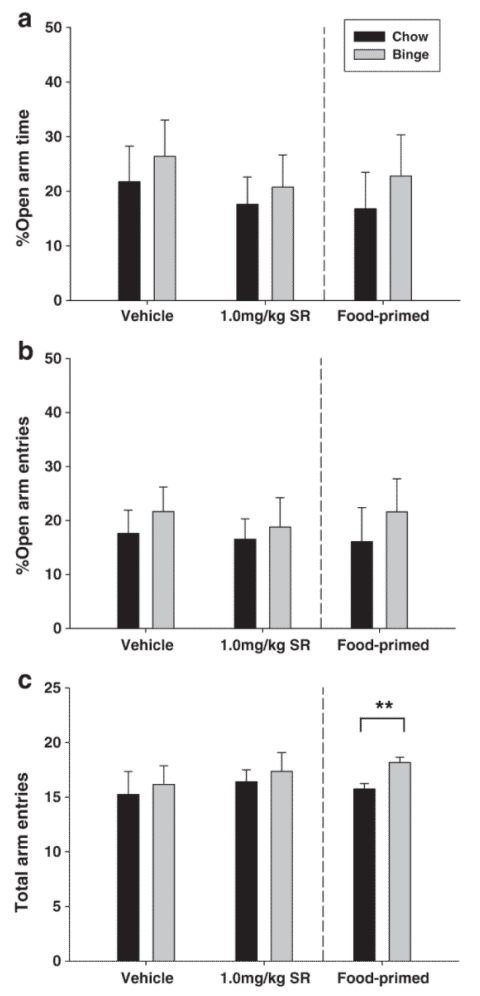

Fig. 4.

No evidence of increased anxiety-like behavior on the elevated plus-maze $24 \mathrm{~h}$ following last sweet fat diet access in rats with binge-like intake history. Separate groups of rats were treated (i.p.) with vehicle, or the $\mathrm{CB}_{1}$ antagonist SR147778, or given a food prime prior to being placed on the maze. For food priming, rats received 3 pellets of sweet fat diet (binge group) or an equivalent weight of standard chow (chow group). Data are expressed as $M$ \pm SEM in panels. a, b) Neither percentage of time spent on the open arms nor percentage of entries into the open arms differed between chow and binge rats under vehicle conditions or following treatment with an anorectic dose of SR147778 in an attempt to "precipitate" withdrawal from the sweet fat diet. Food priming also did not alter open arm time or entries. c) Overall locomotor activity, as measured by total arm entries was enhanced in binge relative to chow rats following a food prime only. Differs from chow $* * p<0.01$. 

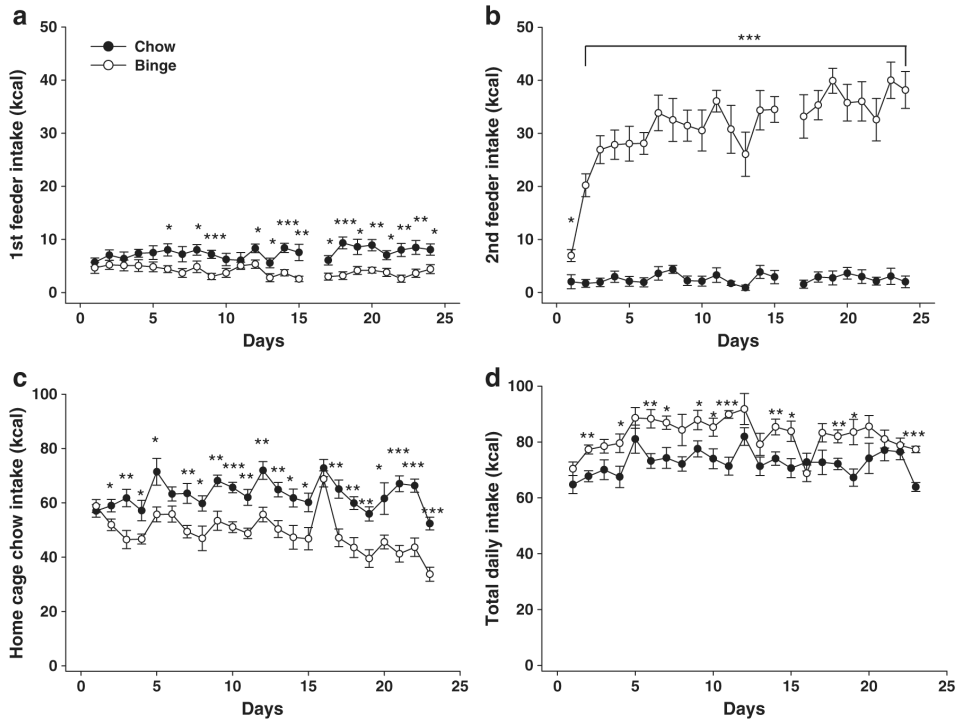

Fig. 5.

Binge-like intake of a sweet fat diet and chow hypophagia in singly housed rats with chow feeder pre-presentation. Two consecutive 10-min feeding sessions were performed, with all rats receiving standard chow from the 1 st feeder. Binge rats received the sweet fat diet in the 2nd feeder, whereas chow rats again received standard chow. Data are expressed as $M \pm$ SEM in panel a) 10-min intake (kcal) of standard chow from the 1 st feeder is reduced in binge rats in anticipation of receiving the sweet fat diet from the 2 nd feeder. b) Binge rats escalate 10min intake of the sweet fat diet from the 2 nd feeder at levels comparable to those seen in group-housed animals with only a single feeder presentation. c) Ad libitum home cage intake of standard chow during the intervening time between binge sessions was decreased in binge rats. d) Total daily combined intake of both standard chow and the highly palatable diet. Binge rats consumed more kcal cumulatively across the study period than chow rats. Differs from chow $* p<0.05, * * p<0.01$, and $* * * p<0.001$. 



Fig. 6.

No evidence of CRF-driven binge-like intake or increased anxiety-like behavior in singly housed rats with chow feeder pre-presentation. Data are expressed as $M \pm S E M$ in panels. a) Pretreatment with the $\mathrm{CRF}_{1}$ antagonist R121919 did not impact 10-min intake of either standard chow or sweet fat diet. b) R121919 treatment also did not alter home cage chow intake in either chow or binge rats. c) On the elevated plus maze, percentage of time spent on the open arms, percentage of entries into the open arms, and overall locomotor activity as measured by total arm entries did not differ between chow and binge rats at $24 \mathrm{~h}$ after the most recent binge. d) During a defensive withdrawal task, binge rats emerged more rapidly from a darkened withdrawal chamber than chow rats when tested $48 \mathrm{~h}$ after the most recent binge. Total time inside the withdrawal chamber and total number of withdrawals did not differ significantly between diet groups. Differs from chow $* p<0.05, * * p<0.01$, and $* * * p<0.001$. 


\section{Table 1}

Increased weight gain and adiposity in female rats with a history of binge-like sweet fat diet intake.

\begin{tabular}{lcc}
\hline & Chow $(\boldsymbol{n}=\mathbf{3 2})$ & Binge $(\boldsymbol{n}=\mathbf{3 1})$ \\
\hline Body weight gain $(\mathrm{g})$ & $59.3 \pm 2.9$ & $69.2 \pm 2.5^{*}$ \\
Feed efficiency (mg weight gain/kcal consumed) & $21.2 \pm 1.0$ & $23.9 \pm 1.8^{*}$ \\
Fat mass (g) & $39.8 \pm 1.6$ & $47.2 \pm 2.0 * *$ \\
Lean mass (g) & $197.0 \pm 3.2$ & $199.9 \pm 2.6$ \\
\hline
\end{tabular}

Data represent $M \pm \mathrm{SEM}$.

All measurements represent values after 40-41 days of binge-like access.

Differs from chow $p<0.05$.

Differs from chow $p<0.01$. 


\section{Table 2}

Plasma corticosterone levels $(\mathrm{ng} / \mathrm{mL})$ and 10-min food intake in binge and chow rats under unstressed and restraint stressed conditions.

\begin{tabular}{lccccc}
\hline & \multicolumn{2}{c}{ Chow $(\boldsymbol{n}=7)$} & & \multicolumn{2}{c}{ Binge $(\boldsymbol{n}=8)$} \\
\cline { 2 - 3 } \cline { 5 - 6 } & Unstressed & Stressed & & Unstressed & Stressed \\
\hline Baseline $(0 \mathrm{~min})^{a}$ & $233 \pm 64$ & $177 \pm 41$ & & $214 \pm 31$ & $279 \pm 44$ \\
Post-stress $(60 \mathrm{~min})$ & $249 \pm 43$ & $717 \pm 334$ & & $229 \pm 35$ & $647 \pm 220$ \\
Post-binge $(160 \mathrm{~min})^{c}$ & $241 \pm 68$ & $142 \pm 20$ & & $217 \pm 31$ & $185 \pm 27$ \\
10 min intake (kcal) & $6.69 \pm 1.13$ & $5.13 \pm 1.28$ & $23.87 \pm 3.63$ & $21.56 \pm 3.06$ \\
\hline
\end{tabular}

Data represent $M \pm \mathrm{SEM}$.

${ }^{a}$ Baseline samples collected immediately prior to the daily $2 \mathrm{~h}$ food deprivation period.

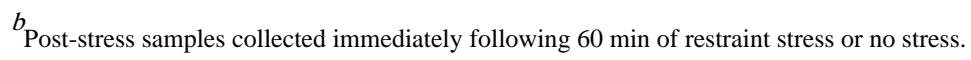

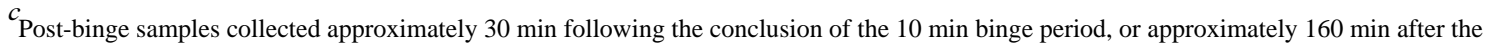
baseline measurement. 